\title{
Collision tumor of ovary: A rare entity
}

\author{
DikshaKarki ${ }^{1}$, Smriti Karki ${ }^{2}$, Purbesh Adhikari ${ }^{3}$, Mona Dahal ${ }^{4}$, Milan Adhikari ${ }^{5}$, \\ Bindu Adhikari ${ }^{6}$
}

1,4Senior Resident/Lecturer, ${ }^{2}$ Professor, ${ }^{3}$ Assistant Professor, ${ }^{5,6}$ Junior Resident, Department of Pathology, BP Koirala

Institute of Health Sciences, Dharan, Nepal

\section{A B S T R A C T}

Collision tumors are composed of two histologically distinct neoplasms in the same organ without intermixture of cell types. The co-occurrence of a serous adenocarcinoma with a mature cystic teratoma is very rare. We present here the case of a 48 years married female with bilateral high grade serous carcinoma of the ovary with left sided mature cystic teratoma.

Key words: Collision tumor; Mature cystic teratoma; Serous carcinoma

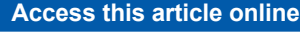

Website:

http://nepjol.info/index.php/AJMS DOI: 10.3126/ajms.v9i4.20054 E-ISSN: 2091-0576 P-ISSN: 2467-9100

\section{INTRODUCTION}

Collision tumors represent a coexistence of two histological distinct tumors without admixture in the same tissue or organ. ${ }^{1}$ These tumors have been described in other organs such as liver, kidney, brain, lung, stomach, esophagus and bone but their occurrence in ovary is rare. ${ }^{2}$ Coexistence of tumors has been reported in the ovary, such as serous cystadenoma and teratoma $\mathrm{e}^{1,3}$ serous papillary cystadenocarcinoma and granulosa cell tumor, serous adenocarcinoma and steroid cell tumor, teratoma with granulosa cell tumor ${ }^{4}$ and mucinous cystadenoma and teratoma. ${ }^{5}$ However, ovarian collision tumors are most commonly composed of teratoma and cystedenoma or cystadenocarcinoma. ${ }^{4}$ Here in, we describe a case of bilateral high grade serous carcinoma of the ovary with left sided mature cystic teratoma.

\section{CASE HISTORY}

A 48 years old married female (parity 5, live 5) presented in gynaecological outpatient clinic with complain of abdominal distension and mild abdominal pain. Her menstrual history was normal and obstetric history was uneventful. She denied weight loss, fever, vomiting, vaginal discharge. The past medical history was unremarkable. Routine hematological parameters were within normal limit. Abdominal sonography revealed solid cystic bilateral adnexal masses with moderate ascites. A diagnostic ascitic fluid tap was performed and subjected for analysis. Ascitic fluid cytology revealed tumor cells in sheets and 3D clusters favoring a diagnosis of metastatic adenocarcinoma. A preoperative diagnosis of ovarian carcinoma with metastasis was made and bilateral salpingooophorectomy, with omentectomy and peritoneal wall biopsy was performed.

Grossly, both ovaries were grossly replaced by tumor with multiple areas of capsular breach and surface nodular deposits on right ovary whereas outer surface of left ovary is smooth. Right ovary was $2.5 \times 2 \times 1.2 \mathrm{~cm}$, cut surface showed solid soft to firm areas with cystic areas of size $2 \times 1.4 \mathrm{~cm}$ (Figure 1). Left ovary was enlarged and measured $4.5 \times 4 \times 2 \mathrm{~cm}$. Outer surface is smooth. Cut surface showed solid cystic areas (Figure 2). Solid area was grey white in colour, firm in consistency with papillary excrescences and areas of hemorrhages. Cystic area of size $2 \mathrm{~cm}$ was identified which was filled with cheesy material. Bilateral fallopian tubes showed surface nodules. Omentum showed multiple tumor deposits ranging in size from 0.5 to $1 \mathrm{~cm}$.

Microscopic examination of the right ovary showed high grade serous carcinoma in the form of papillae (Figure 3); glands and solid sheets of tumor cells with moderately pleomorphic hyperchromatic to vesicular 
nuclei, conspicuous nucleoli and moderate cytoplasm. Large bizarre cells along with multinucleated forms and numerous mitotic figures including atypical ones are also seen. Large areas of psammoma bodies are also present (Figure 4). Capsular breach of right ovary was noted. The left ovary showed high grade serous carcinoma with adjacent area revealing a cyst lined by keratinized stratified squamous epithelium with keratin flakes and underlying adipose tissue, cartilage (Figure 5) and thyroid parenchyma (Figure 6). Bilateral fallopian tubes also showed high grade serous carcinoma. Omental biopsy and peritoneal biopsy showed presence of metastatic tumor deposits.

\section{DISCUSSION}

High grade serous carcinoma is the most common type of ovarian cancer accounting for approximately $50 \%$ of ovarian carcinomas. Nearly all patients present in advanced stage with tumor disseminated throughout the abdominal

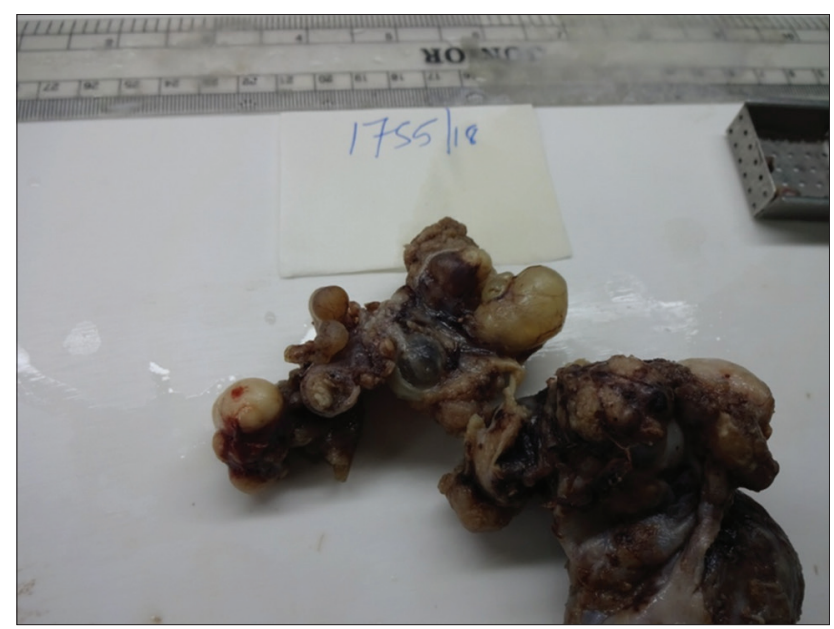

Figure 1: Gross photograph of ovary and fallopian tube. Both the ovary and fallopian tube are replaced by a tumor

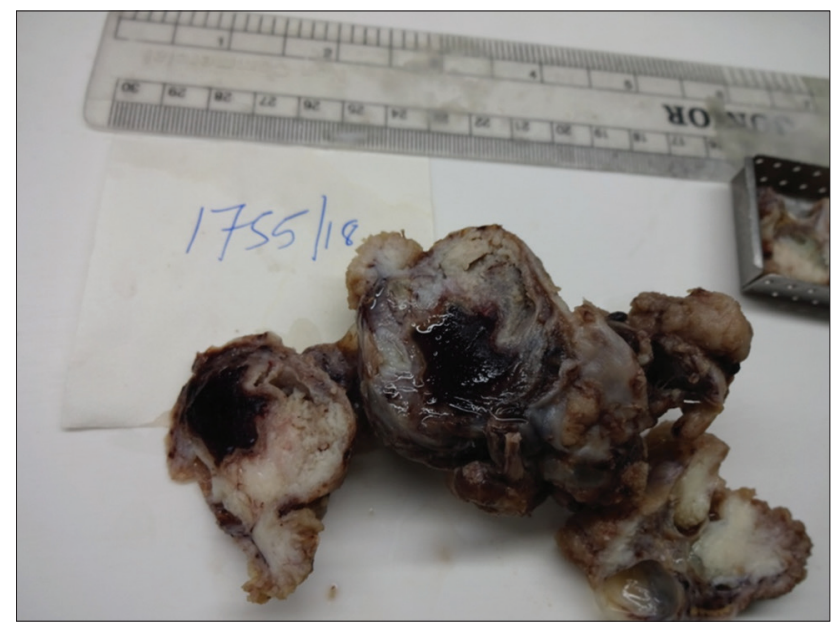

Figure 2: Cut section of the ovary showing solid cystic areas and pelvic cavities. ${ }^{6}$ Mature cystic teratoma (MCT) is the most common type of ovarian germ cell neoplasm and constitute $20 \%$ of all ovarian neoplasms. The tumor is composed of well-differentiated derivatives of the three germ layers- ectoderm, mesoderm and endoderm. ${ }^{6} \mathrm{MCT}$ are usually uniloculated with average size of $7-8 \mathrm{cms}$ and can undergo malignant transformation in $1 \%$ of cases. ${ }^{7}$ Collision tumors represent a coexistence of two adjacent but histologically distinct tumors, without histologic admixture in an organ. We present this case because collision tumors in ovary are a rare entity and rarer is the combination of high grade serous carcinoma with teratoma, as in our case.

In 2015, Bhagat and Dey reported a collision tumor comprising of bilateral high grade serous carcinoma of ovary and a mature cystic teratoma with multiple tumor deposits in omentum. ${ }^{2}$ Similar finding was noted in our case. Kocak and Nalbant in 2015 also presented a case

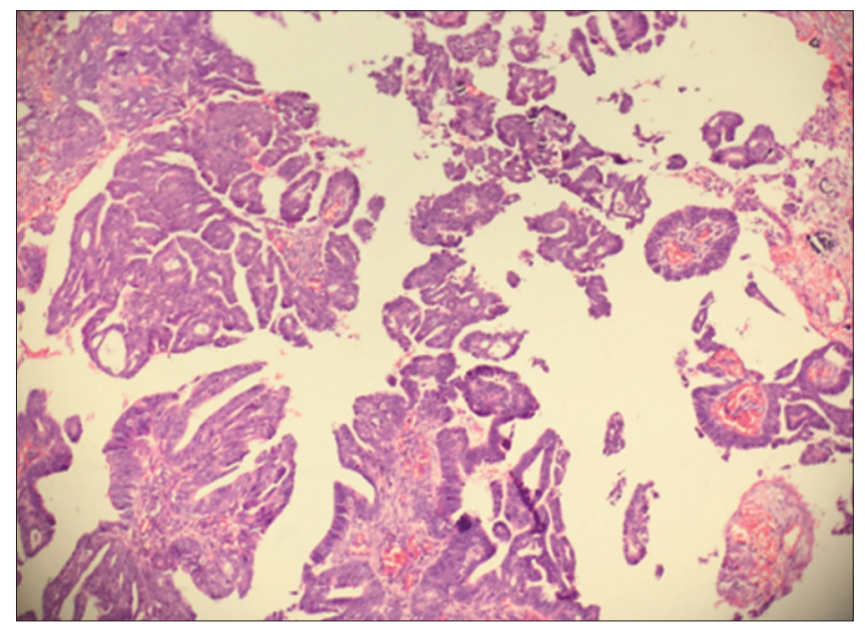

Figure 3: Photomicrograph showing tumor cells arranged in papillae (Hematoxylin and Eosin stain, 40x)

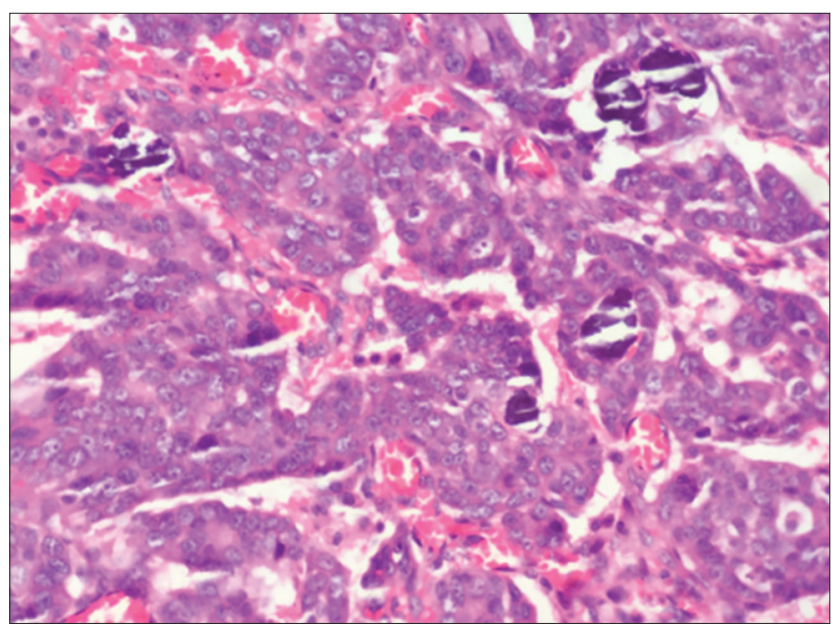

Figure 4: Photomicrograph showing moderately pleomorphic tumor cells with numerous psammoma bodies (Hematoxylin and Eosin stain, 400x) 


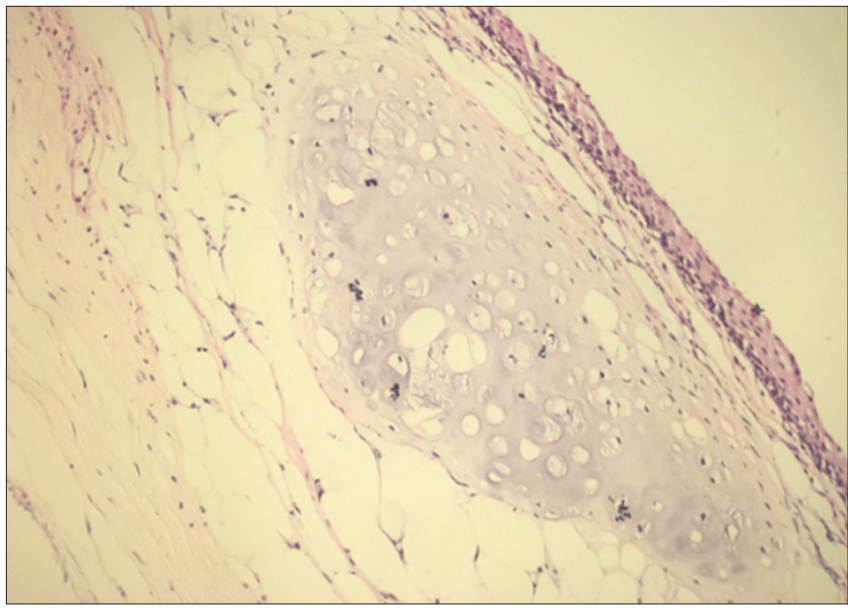

Figure 5: Photomicrograph showing stratified squamous epithelium with mature cartilage and adipose tissue (Hematoxylin and Eosin stain, 400x)

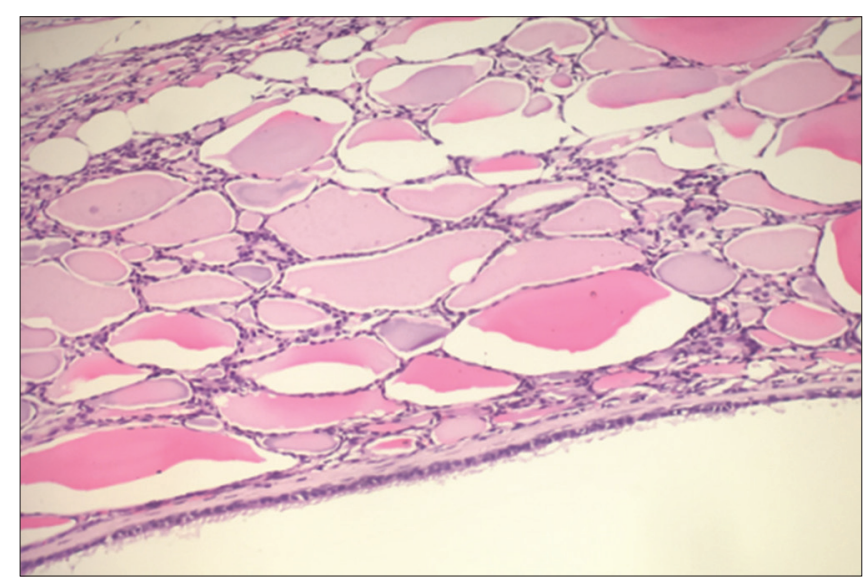

Figure 6: Phtomicrograph showing ciliated columnar epithelium with thyroid follicle (Hematoxylin and Eosin stain, 400x)

of 83 years old female with collision tumor composed of invasive Serous Papillary cystadenocarcinoma and mature cystic teratoma. ${ }^{8}$

The common collision tumors of the ovary comprise of mature teratoma with mucinous cystadenoma. Okada et al, have reported eleven cases of mucinous tumors coexisting with dermoid cysts out of which 6 were benign, 3 were lowgrade, and 2 were malignant. ${ }^{9}$ Shetty et al reported a case of uterine papillary serous carcinoma with mature cystic teratoma of left ovary in a post menopausal woman. ${ }^{7}$ A triple coexistence of collision tumor comprising of serous cystadenoma, mature cystic teratoma and hemorrhagic follicular cyst has also been reported by Papaziogas et al in 2007. ${ }^{10}$ Malignant transformation of mature cystic teratoma has been described in various literature ${ }^{11,12}$ however no such findings has been detected in our case.

Pelvic examination, CA 125, and transvaginal ultrasound are currently used screening tests, however ultrasound examination is the most useful noninvasive diagnostic test. ${ }^{13}$ The level of CA 125 is raised in $80 \%$ of patients with ovarian carcinomas. In our case, the levels CA 125 was above normal ranges.

Mature cystic teratoma forms a common component of ovarian collision tumors and identifying the other component is important because the treatment and prognosis vary. Thorough sampling of the specimen is required so that one does not miss a tumor occurring in collision with a mature cystic teratoma.

\section{CONCLUSION}

Ovarian collision tumors are rare, but even rarer are the coexistence with malignant ovarian tumors, as in our case. The preoperative suspicion of the existence of such tumors would help the pathologist to perform a thorough examination of the excised specimen, so as to avoid misdiagnosis of a second type of tumor. Pathologist and surgeons need to be aware of existence of collision tumors, as it is important to correctly diagnose the various component of tumor for treatment and better outcome of the patient.

\section{ACKNOWLEDGEMENT}

I am grateful to Dr Purbesh Adhikari, Assistant Professor, Department of Pathology, BPKIHS, for providing an insight about the case.

\section{REFERENCES}

1. Pal Sharan J, Dorothy LF, Nayak SR, Arun R and Deepika B. Collision Tumors of Ovary: A Rare Entity. International Journal of Innovative Research \& Development. 2014; 3(7):424-427.

2. Priyanka B and Pranab D. Bilateral serous adenocarcinoma of ovary coexisting with mature cystic teratoma: Case report and review of literature. Annals of Pathology and Laboratory Medicine 2015;2(2):71-74.

3. Choudhary S and Adisesha S. Collision tumors of ovary: A rare phenomenon. International Journal of Case Reports and Images 2012; 3(10):68-70.

4. Fatima GQ, Suman V, Kumar BN, Ajay BR, Dharmendra and Gauri LA. Collision tumor: Bilateralmucinous adenocarcinoma coexisting with dermoid cyst in an ovary: An extreamly rare case. International Journal of Advanced Research and Review 2016;1(12):14-19.

5. Singh AK and Monika Singh M. Collision Tumours of Ovary: A very rare case series. Journal of Clinical and Diagnostic Research 2014;8(11): 14-16.

6. Aleksander T and Russell V. In: Kurman J. Robert, Ellenson Hedrick Lora and Ronnett M. Brigitte, editor. Blaustein's Pathology of the Female Genital Tract. $6^{\text {th }}$ ed: Springer Science and Business Media, LLC 2011. pp. 847-907.

7. Shetty PK, Balaiah $\mathrm{K}$ and Bafna UD. Uterine papillary serous carcinoma with mature cystic teratoma of left ovary. Online $\mathrm{J}$ Health Allied Scs 2010;9(3):19. 
8. Cengiz K and Melike N. Collision Tumor of Ovary: Invasive serous papillary cystadenocarcinoma and mature cystic teratoma. Scholars Journal of Medical Case Reports 2015; 3(11):1026-1031.

9. Okada S, Ohaki Y, Ogura J, Ishihara M, Kawamura $T$ and Kumazaki T. Computed tomography and magnetic resonance imaging findings in cases of dermoid cyst coexisting with surface epithelial tumors in the same ovary. Journal of Computer assisted tomography 2004; 28(2):169-173.

10. Papaziogas B, Souparis A, Grigoriou M, Tsiaousis P, Kogia E, Panagiotopoulou $\mathrm{K}$ and Atmatzidis $\mathrm{K}$. A rare triple coexistence of a collision tumor, a benign mature cystic teratoma and a hemorrhagic follicular cyst of the ovaries. The Internet Journal of
Surgery 2007;14(1).

11. Jitsumori M, Munakata $S$ and Yamamoto T. Malignant Transformation of Mature Cystic Teratoma Diagnosed after a 10-Year Interval. Case Reports in Obstetrics and Gynecology Volume 2017, Article ID 2947927, 4 pages

12. Shramana Mandal and Bhawana A. Badhe. Malignant transformation in a mature teratoma with metastatic deposits in the omentum: A Case Report. Case Reports in Pathology Volume 2012 Article ID 568062, 3 pages.

13. Jelovac $D$ and Armstrong DK. Recent progress in the diagnosis and treatment of ovarian cancer. CA Cancer J Clin 2011; 61:183203.

\footnotetext{
Author's Contribution:

Orcid ID:

Dr. Diksha Karki-D https://orcid.org/0000-0002-5399-2029,

Dr. Smriti Karki- ohttps://orcid.org/0000-0003-1907-4061

Dr. Purbesh Adhikari- https://orcid.org/0000-0001-6278-7855

Dr. Mona Dahal - https://orcid.org/0000-0002-1226-3372

Dr. Milan Adhikari- https://orcid.org/0000-0003-2938-2455

Dr. Bindu Adhikari-(D) https://orcid.org/0000-0002-8455-8866
}

DK- Design of the case report, review of the literature, literature search, preparation of the case report and critical revision of the case report; SK- Expert opinion about the case; PA-Concept, review of the case report and review of literature; MD- Concept, review of the case report and review of literature; MA- Helped in history taking, literature search and photography; BA-Helped in history taking, literature search and photography

Work attributed to: Department of Pathology, BP Koirala Institute of Health Sciences, Dharan, Nepal

Source of Support: Nil, Conflict of Interest: None declared. 